Canadian Journal of Family and Youth, 13(3), 2021, pp. 391-396

ISSN 1718-9748@ University of Alberta

http://ejournals,library,ualberta.ca/index/php/cjfy

\title{
Childhood Sex Education in Canada
}

Carly Bruce, MacEwan University

\section{Introduction}

The topic of sex education in childhood is multi-faceted and highly controversial. There are many arguments over what should be considered age-appropriate, how we must protect the innocence of the children, the insistence on religious beliefs being prioritized, as well as the ease of access children have to sexually explicit material through what they view in the media and on the internet. Canada's sex education lacks unity and federal guidance, as it differs from province to province to territory, and is focused largely on preventing teen pregnancy, sexually transmitted infections, and other negative sexual outcomes, and in some cases being completely abstinence focused (Action Canada for Sexual Health \& Rights, 2020). It is this paper's position that this limited and narrow-sighted sex education does not match the sexual development stages of children, should be enhanced to better aid in recognition of child sexual abuse cases, and that the absence of LGBTQIA+ representation puts the well-being of students in danger. If the true interest of parents who oppose a more comprehensive sex education curriculum is protecting the children and their innocence, they need to look at the facts of the benefits of such a curriculum and re-evaluate their possible personal biases. Following is a deep look at Canada's current state of sex education, an examination of how it could be improved, an acknowledgement of, and answer to parental push-back, and provides some insight on the positive benefits of a more comprehensive sex education curriculum for children up to the age of 14 .

\section{Discussion}

In an exploration of the current province and territory-based sex education curricula, Action Canada for Sexual Health \& Rights (2020) found that there was a substantial amount of disconnect and inconsistency, an absence of any type of monitoring from anyone in a position above the teachers, and that none of the curricula met the criteria set out by the U.N for a comprehensive sex education. The majority of sex-ed curricula being outdated, sourcing between 2000-2012 (dependent on which province or territory is being looked at), and the highly politicized nature of what is included and removed from lessons contribute to an incomplete, sub-par, and stagnant level of education that is being delivered to children in Canada (Action Canada for Sexual Health \& Rights, 2020). In a brief, anecdotal, one question survey put forth by the author of this paper, it was found that out of 26 responses, $100 \%$ of participants felt they did not receive an adequate level of sex education to prepare them for real life outside of the classroom. Although some provinces and territories are doing a better job at 
teaching more extensively on some topics beyond prevention, there are still too many that are uniformly not included: such as gender identity, abortion, and the pleasure aspect of sex according to the province-by-province checklists provided by Action Canada for Sexual Health \& Rights (2020). This lack of education goes beyond what is being taught to students and extends to how educators are being trained at all levels of education; when examining thirty Ontario post-secondary Early Childhood Education programs being offered, Balter et al. (2018) discovered that none of them required any courses on sex and gender development. This lack of training led early childhood educators that were interviewed in this study to lack confidence in their ability to address sex and gender related issues, and an inability to decipher what was considered normative behaviour in students versus what type of behaviour should warrant concern. This is not to say that these educators were against more comprehensive sex education for preschool aged children, as many had suggestions on how they could be better trained in these areas (Balter et al., 2018). This lack of comprehensive curricula across Canada and the absence of proper training for educators leaves children's physical and mental well-being at risk; this paper will explore the many elements of this claim.

According to Statistics Canada, in the year 2016, 5,096 children under the age of 12 were victims of sexual offences and 6,483 children between the ages of 12-15 were also victims of sexual offences (Statistics Canada, 2016). Wurtele \& Kenny (2016) state that "children who don't know about these two topics - sexuality and body safety - are more vulnerable to sexual abuse" (p. 2) and that children knowing the proper names of genitals, as opposed to made up terms or nicknames for their genitals, aid in earlier recognition and acknowledgment by those adults in positions of authority that child sexual abuse may be occurring. They even go as far as acknowledging that "some sexual offenders avoid children who know the correct names for their genitals, because this suggests the children have been educated about body safety and sexuality" (Wurtele \& Kenny, 2011, p. 5). This early understanding and ability to effectively communicate about body parts and ability for a child to recognize what is inappropriate sexual behaviour is absolutely paramount in providing intervention when an adult is able to easily recognize when a child is being sexually abused, and could save the child from continued abuse. Action Canada for Sexual Health \& Rights states that "sex-ed is one piece of the puzzle in preventing gender-based and sexual violence" (2020, p. 78). There is no possible better way to protect a child's innocence than sparing that child from being sexually abused.

Beyond safety from sexual abuse, knowing proper genital names and understanding age appropriate levels of sexual behavior also contributes to a child having a "healthy, more positive body image" (Wurtele \& Kenny, 2011, p. 4) and aids in their understanding of what they have begun discovering about their own body as well as others. Although we may be worried about exposing young children to sexual topics at too early of an age, it is known that infants discover their genitals as early as 6-8 months for boys and 10-11 months for girls and are engaging in types of sexual play by the age of 6-8 years old (Wurtele \& Kennedy, 2011). We are also seeing a "secular trend toward earlier maturation" (p. 166) in the last 60 years as girls and boys are beginning to hit puberty earlier than past generations (Shaffer et al, 2020). This early discovery and exploration of genitals, as well as this apparent earlier onset of puberty should serve as evidence not only that children can handle earlier, and more comprehensive sex education, but that they need it in order to develop healthy relationships with their bodies as well as proper understanding of age-appropriate and normative sexual behaviour.

An important demographic is also largely being left out of the conversation when it comes to Canadian children's sex education; the LGBTQIA+ communities of Canada. This can have negative effects not only on those children who identify as a part of these communities, 
but also their heterosexual cisgender classmates. Action Canada for Sexual Health \& Rights (2020) states that "sex-ed gives young people the knowledge and skills to be themselves, to live their truth and values, and to challenge rigid gender norms" (p. 8). Childhood is a time for creativity, self-discovery and imagination without the societal pressures of adulthood; we should allow this self-discovery and creativity to be extended to include sexual and gender expression led by proper and safe sex education. Bialystok (2018) states that "LGBT students depend on a universal program of antihomophobia education for their freedom and well-being" (p. 23) as well as discusses the need for not leaving sex education up to parents who are potentially homophobic, as this would go against the child's rights to a comprehensive education. With an ever increasing number of young people being more comfortable with gender fluidity, rising from the current $4-10 \%$ of people identifying as something other than heterosexual or cisgender according to Action Canada for Sexual Health \& Rights (2020), our sex education must also expand and diversify. If we create a space where it is safe to be LGBTQIA+ and these matters are being accurately spoken on, we can create a safer space for every student, whether they conform to a heterosexual and/or cisgender identity or they do not. In $2021 \mathrm{we}$, as a society, must recognize the calls of members of LGBTQIA+ communities for greater recognition in the area of sex education as a means to aid children in discovering new identities they may not be exposed to, as well as a means to protect those children from bullying and abuse. Action Canada for Sexual Health \& Rights (2020) interviewed student participants across Canada and found that there was an overwhelming number of responses echoing the sentiment that these students felt let down by the negative, and limited focus of their education and that they would have appreciated a more extensive curriculum. With that being said, if the aforementioned educators are eager to be better trained to deliver effective lessons surrounding sexual health and identity, and the students are crying out to learn more than they are currently being taught; who is responsible for the slow progress being made in this area of education? In short, the policy makers and the parents.

One thing that has long held back Canada's overall progression to a more complete sex education curriculum is the push-back the government and schools have received from parents dictating what they feel their children should not have to endure learning. This is exemplified by the hundreds of students who were pulled from a Toronto school by their parents when the new sexuality education curriculum was announced in Ontario. This push-back can be sourced to the values of the parent being influenced by their religion or beliefs about LGBTQIA+ rights and lifestyles, as many of the parents quoted deny their homophobia while simultaneously asserting that their children should not be forced to endure learning about homosexual identities, sex and relationships (Bialystok, 2018). If these parents had received a more comprehensive and modern education on sexuality and other sex and gender identities, maybe they would not be as fearful of the consequences of their children learning more than they did. Dyer (2019) goes so far as to explore the idea that this practice of parents disagreeing with aspects of a curriculum and pulling their children from the class is an expression of how parents, and adults in general "are implicated in imposing our own ideologies, fantasies and anxieties onto the child's world" (p.743). There is great debate over whether it is the parent's right to remove the child from learning about topics they deem to be inappropriate or whether that action, in itself, goes against the rights of the child to a comprehensive sex education set out by the 2018 UNESCO Technical Guidance on Sexuality Education (Action Canada for Sexual Health \& Rights, 2020). In reference to the allowance of parents to show their dissent by opting their children out of classes, it is the view of Bialystok (2018) that "parents' rights are not being violated by making such a curriculum mandatory, whereas children's rights may be violated 
by leaving the teaching of sexuality to the discretion of their families" (p.14). We should not be allowing some parents' religious beliefs or prejudice against sexual minorities dictate the level of education their child is receiving. This would not only be beneficial to expand the minds and worldviews of those children that would be opted-out by their parents, but also beneficial to their peers, as there would be less of a chance the child would adopt their parents' homophobic beliefs and act out against sexual and gender minority classmates.

This is not all to say that the varying curricula across Canada are inherently or completely terrible, but rather that they have a far way to go if we want our children to grow into adults with healthy sexual relationships and positive body image. Although highly contested, Ontario's 2015 update to their sex education curriculum moved a step in the right direction as it included information on sex and gender identities, navigating the digital world of sexting and social media, as well as discussing consent (Dyer, 2019). These are important areas for children to learn about in sex-ed, especially those who would not be receiving this information from their families or church groups. In today's world, children at younger and younger ages are being exposed to sexual content through social media, the vastness of the internet and the media; we must ensure that the level of education they are receiving matches this increase in exposure if we want to ensure their physical and mental well-being. In a very recent proposed update to the Alberta school curriculum, consent is set to be taught at an earlier age ("Draft K-6 Curriculum, alberta.ca, 2020). In the "Key Themes" category, under the "Consent" sub-heading, it is stated that "consent will be taught as an essential part of the health and wellness curriculum". This section goes on to discuss how in early years this will take the form of teaching children that "personal boundaries can be communicated through words and actions" before moving onto sex-related consent at more age appropriate levels. I applaud this small step in the right direction as it seeks to teach boundaries and consent as early as kindergarten, and this is an important lesson in developing a healthy relationship with oneself, as well as with others in later years.

There are also programs put on by organizations outside of the school curriculum in Alberta that work to aid in teaching children about important sex education related issues; one of these organizations is the Sexual Assault Center of Edmonton (SACE). For educators working with children at a preschool level the Sexual Assault Center of Edmonton has a program called "The Safe Preschoolers Education and Awareness Kit" (SPEAK). This program is led by members of SACE's public education team and aims to "offer detailed information on how to identify indicators of sexual abuse, how to respond to children's disclosures, and how to report child sexual abuse" (sace.ca, 2020). This is the type of training that the Ontario Early Childhood Educators were calling out to be more readily available to them (Balter et al. 2018). I believe that if this program was better funded, utilized by the governments across Canada and more heavily encouraged and funded, we could see a decline in continued child sexual abuse. SACE does not stop their public education at preschool level, they also have programs for students starting in grade 7 discussing sexual harassment, as well as the sharing of sexually explicit photos; areas largely left out of Canadian sex education at this point (sace.ca, 2020). Although these are all positive steps and there is great value in what is being done by the Sexual Assault Center of Edmonton, there are too many benefits to a comprehensive sex education to miss out on any further. Such benefits are laid out by Action Canada for Sexual Health \& Rights (2020) in their State of Sex Education exploration and are listed to include "delayed initiation of sexual intercourse, increased condom use, increased contraception use, improved attitudes related to sexual and reproductive health" and others (p. 6). While this paper 
is willing to acknowledge that there has been recent progress made, it also holds the position that there are many large steps still to be made if protecting children is the ultimate goal of sex education in Canada.

\section{Conclusion}

Through the research of the many factors and ideals that are covered in sex education, the effects they have on a child's life, and an exploration into the current state of sex education in Canada, it can be seen that great improvements must be made. Whether we are to discuss the positive effects of adding a better range of topics to the curriculum, better training for educators, or the negative effects of the allowance of parents to opt their children out of receiving a complete education; there is no evidence that our current system is effective. We must rally on the side of students, their educators, and those in the LGBTQIA+ communities and demand that our provincial and federal governments update the education that children are receiving to better align with the ideals put forth by the U.N. If we truly want to protect the innocence of our children, a sentiment put forth by many parents in response to the updated Ontario curriculum (Bialystok, 2018), we must do so by protecting them from repeated child sexual abuse, and aid them in developing more healthy and complete perspectives on sexual health and identity. This paper puts forth a call to action; to parents, educators, and the provincial and federal governments to work together, set aside our differences and out-dated thinking, and provide today's children with a more comprehensive sex education curriculum. This will not be a reality unless the majority rallies together and instills mass change in this area. The children are ready and so are the educators, the rest of society and the government need to catch up and work to update our out-dated and sub-par level of sex education for children, even before they become teens and young adults. 


\section{References}

Action Canada for Sexual \& Health Rights. (2020, April 3). The State of Sex-ed In Canada. https://www.actioncanadashr.org/resources/reports-analysis/2020-04-03-state-sex-edreport

Alberta Government. (2020). Draft K-6 Curriculum. "Key Themes". https://www.alberta.ca/curriculum.aspx?utm_source=google\&utm_medium=sem\&ut m_campaign=K6curriculum\&utm_term=curriculum\&utm_content=v1

Balter, A.-S., van Rhijn, T., \& Davies, A. W. J. (2018). Equipping early childhood educators to support the development of sexuality in childhood: Identification of pre- and postservice training needs. Canadian Journal of Human Sexuality, 27(1), 33-42. https://doi.org/10.3138/cjhs.2017-0036

Bialystok, L. (2018). "My Child, My Choice"? Mandatory Curriculum, Sex, and the Conscience of Parents. Educational Theory, 68(1), 11-29.

Dyer, H. (2019). The Contested Design of Children's Sexual Education: Queer Growth and Epistemic Uncertainty. Gender and Education, 31(6), 742-755.

Shaffer, D. R., Kipp, K., Wood, E., Willoughby, T., Roberts, K., Gottardo, A., Krettenauer, T., Lee, J. \& Newton, N. (2019). Developmental Psychology: Infancy and Childhood (5th Canadian Ed.). Nelson Education Ltd. Toronto, ON.

Sexual Assault Center of Edmonton. (2020). Public Education. https://www.sace.ca/services/public-education/\#1550598975449-b55e2d75-2ea4. Retrieved on April 1, 2021.

Statistics Canada. (2016). Victims of police-reported violent crime in Canada, 2016. https://www150.statcan.gc.ca/n1/pub/85-002-x/2018001/article/54960/s1-eng.htm. Retrieved on April 1, 2021.

Wurtele, S. K., \& Kenny, M. C. (2011). Normative Sexuality Development in Childhood: Implications for Developmental Guidance and Prevention of Childhood Sexual Abuse. Counseling \& Human Development, 43(9), 1-24. 
Bruce 
Bruce 